\title{
Research on the Educational Issues of the Emerging Tourism Industry in Developing Countries
}

\author{
Chao Feng*, Di Wu \\ Business School, Xiangtan Institute of Technology, Xiangtan 411104, China \\ *Corresponding author: Chao Feng, cstdxy2008@126.com
}

\begin{abstract}
This research explores emerging concepts of tourism education, training, and entrepreneurship development. Nowadays, the discourses on this theme have been growing in both developed and developing countries, especially to reduce unemployment rates through the education of young people. For this purpose, this study uses secondary data sources to analyze individual rationality and the creativity of educated young people for entrepreneurship development in the business sector. The analytical framework begins from the investigation of the tourism industry and the processes for empowering those people since tourism industry is considered as one of the agents of economic changes in developing countries, such as Nepal. However, skilled and trained manpower are required to operate well. The main theme of this study is that the aforesaid manpower can be developed with entrepreneurship skills by providing education and training in this business. This study entirely agrees that once the tourism industry is well run by removing the hurdles seen in this sector, there would be an increase in employment opportunities and a raise in the country's revenue in addition to solving many other social problems.
\end{abstract}

Keywords: Tourism industry; Diversity; Immaturity; Entrepreneurship; Education; Training

Publication date: December 2021; Online publication: December 23, 2021

\section{Introduction}

The United Nations World Tourism Organization (UNWTO) defined the term "tourism" as "the activities of persons traveling to and staying in places outside of their usual environment for not more than one consecutive year for leisure, business, and other purposes." Tourism includes movement from one place to another, accommodation at the place of destination, and any activities undertaken in the process ${ }^{[1-4]}$. Leisure activities are most commonly associated with business to be the primary motivation for travel, as well as "other purposes," which may include health, education, or visiting family and friends ${ }^{[4,5]}$.

Tourism education is an emerging concept in the field of entrepreneurship development in many developing countries, such as Nepal. It provides a clear conceptual framework regarding the relationship between the tourism industry and education. It helps to bring the interface of tourism industry and education closer to each another ${ }^{[6-8]}$. Educators and employers are two major players representing a power base at the interface between education and employment ${ }^{[4]}$. According to them, educators and employers have different expectations. Employers seek practical skills, and their focus is on the skill transfer of an individual through education ${ }^{[3]}$. In contrast, the focus of educators is on the development of more tourismspecific materials. This contrasting view creates a gap between employers and educators. It is mainly due to the lack of proper communication, collaboration, educators' involvement in the tourism industry, and the clear role of the industry to promote education. In this context, education and training have become an emerging issue in the field of tourism. Therefore, they represent importance to any attempt to dissect the 
relationship between tourism educators and the industry ${ }^{[4,5,9]}$. In this context, the objective of this study is to unravel the cardinal question - "What is the response of employers to promote entrepreneurship in the tourism industry?".

\section{Materials and methods}

This study is mainly based on secondary data sources. Most of the information collected is from reviews of existing literatures regarding tourism education and entrepreneurship development. Similarly, archive documents, books, journals, and websites have been searched. The data available from different sources have been analyzed on the basis of this classification using both analytical and descriptive methods.

\section{Results and discussion}

\subsection{Tourism education and training}

There is an important distinction which can and should be drawn between tourism education and tourism training since this would influence the type and depth of relationship which exists between the industry and education ${ }^{[10]}$. Training has traditionally dominated the tourism sector, where vocationally-orientated courses have been providing the work-force with the necessary craft skills for many years ${ }^{[11]}$.

The development of training courses which aim to deliver practical knowledge and techniques has historically been linked to the needs of travel and tourism intermediaries; although increasingly, as industry demands a more professional workforce, the provision of these courses has expanded to embrace a much wider set of industrial sectors ${ }^{[10,12]}$.

Tourism education, on the other hand, is relatively new and remains in an early stage of its evolution. Education for tourism focuses on the process which gives an individual a set of principles and the necessary skills to interpret, evaluate, and analyze. This means that it develops the critical capabilities of the students and encourages the understanding of conceptual issues in order to contribute to professional and intellectual development ${ }^{[4,13]}$. While training and education have evolved independently in theoretical terms, training and education in practice are heavily interwoven. In higher level education, for example, training is seen as essential by the industry, which is reflected in the integration of an industrial year into the course structure of a majority of degree courses ${ }^{[10]}$.

The provision of tourism education is a relatively new development, and higher-level courses in tourism are largely a product of the 1980s and the first half of the 1990s ${ }^{[4]}$. The intellectual and institutional infrastructure is, therefore, only now being put in place, and the relationship between education and industry remains very much in its infancy ${ }^{[10,13]}$. While the provision and quality of training and education for tourism have been improving, the tourism industry has traditionally invested in neither ${ }^{[14]}$. However, the late $1980 \mathrm{~s}$ and 1990s have seen a watershed for the tourism industry, and the industrial and economic upheaval which characterized the commercial climate in recent years has placed a greater emphasis on the role and importance of the human resource function in organizational survival ${ }^{[11,15-19]}$.

Key international bodies such as the World Tourism Organization (WTO), American Express, the International Labor Organization (ILO), and the World Travel and Tourism Council (WTTC) have all begun to publicly recognize the fundamental necessity of training and education to ensure a professional and productive tourism industry. This development, at international level, is complemented by an attitude change in the upper echelons of the industry. For many years, training and education have not featured strongly in the culture of tourism companies - even the larger organizations have historically been hesitant about introducing comprehensive development programs - but increasingly, a more positive view is surfacing. The research undertaken by the University of Survey in 1991 has suggested that at least, the larger tourism enterprises are placing more emphasis on both training and education as companies begin to 
understand more about the role of training and education in boosting the companies' profitability, productivity, and turnover ${ }^{[17]}$.

It should be stressed, however, that while individual companies are "seeing the light" and recognizing the potential contribution to organizational efficiency through training and education, an appreciation of the importance of human resource development to the progress of the tourism industry as a whole is also being aroused, especially among the larger players in the industry.

\subsection{Tourism and entrepreneurship development}

Tourism entrepreneurship eliminates social problems; instead, it escalates fiscal growth and development of a country, resulting in the rise of a country's gross domestic product (GDP). The tourism business has been one of the largest, fastest growing sectors in developing country like Nepal, which plays an indispensable role in creating employments ${ }^{[17,20]}$. The contribution of entrepreneurs has never been given due credit, especially in the field of tourism, yet their contribution, either good or bad, has collectively been the impetus for shaping the economic, social, and cultural aspects of a place ${ }^{[21]}$. Therefore, it can be said that the entrepreneurship in tourism has greatly contributed to the development of tourist destinations.

The role of entrepreneurs in the development of a tourist destination came from Butler's Tourism Area Life Cycle Model ${ }^{[15]}$ - "when the number of visitors begins to increase at a destination, locals see the need to provide businesses and services to cater for the visitors' needs and the economic opportunities it provides $[9,15]$,

Both, tourism and entrepreneurship, have been branded as indefinable and hard to measure as there seems to be a converse relationship between the effect of entrepreneurship on tourism and the attention it has received in the tourism literature to date ${ }^{[13,15,21]}$. Gonnsen mentioned that entrepreneurial activities take place early in the development life of a destination (involvement stage). However, it is the outsiders who initiate the entrepreneurship process ${ }^{[22]}$. Barr emphasized on the role of small scale local entrepreneurial initiatives toward the growth of tourism ${ }^{[7]}$.

Generally, the entrepreneurship-profit relationship connection is empirically established in relation to tourism in developing countries ${ }^{[9,10]}$. Echtner examined educational aspects of promoting entrepreneurship ${ }^{[12]}$, Jafari discussed the social cultural issues and the effect of entrepreneurship ${ }^{[21]}$, while Dahles and Bras highlighted a new form or entrepreneurship where indigenous men sought and competed for relationship with western female tourists ${ }^{[13]}$.

With the field investigated problems of local entrepreneurship in South Pacific countries about the tension that exists between the regulators and the entrepreneurs, Neblett investigated the indigenous entrepreneurial activities in the accommodation sector ${ }^{[25]}$.

Most of the aforementioned studies emphasized on entrepreneurial action. Koh provided an anatomy of entrepreneurship in tourism development ${ }^{[22]}$; he mentioned various stages in the process, which include cognition (predisposing), orientation, opportunity search, opportunity assessment, consideration, opportunity pursuit, birth operation, and evaluation. In doing so, a degree of structure and logic is assumed, which is unrealistic and certainly inconsistent with the behavior of tourism entrepreneurs ${ }^{[4,9]}$. The linkage between entrepreneurship and tourism proposed by the study is further consolidated by Faulkner, where each form of entrepreneurial activity is depicted in terms of their potential bearing on the progress of Butler's model ${ }^{[15]}$. Hence, local entrepreneurs are more prevalent in the involvement stage ${ }^{[7]}$, while migrant entrepreneurs are commonly found in the consolidation stage.

According to Faulkner, there are three ways in which tourism entrepreneurs might be the catalyst for change ${ }^{[15]}$. Firstly, by shrewd management during emergencies, the entrepreneur may diminish the competition. Secondly, by superior tactics, the entrepreneur may induce crises for his or her competitors, rendering them less viable. Thirdly, by excessive expansion beyond the carrying capacity and 
environmental sustainability limits.

\section{Hurdles in the tourism industry}

\subsection{Diversity}

Based on secondary information seen in National Park areas, there is no real agreement among the local government, industry, and academics as to what actually constitute the tourism industry; they agree only on the fact that tourism is enormously diverse in terms of the range of sectors it encompasses and the variety of organizations it incorporates ${ }^{[4,17]}$. However, in tourism areas, tourism spans several industrial sectors, and there are differing interpretations of the categories of employment at various skill levels; in addition, the specific needs of each sub-sector of the industry are significantly different ${ }^{[9,10,18]}$.

In a broad interpretation of tourism, its dominant sectors are seen to be accommodation related activities, transportations in different modes, as well as leisure and recreation services. There are also specialized forms of services in both the generating market (e.g., information provision) and at the destination (e.g., guiding and event planning). Some of these activities involve the public sector as a direct provider, or otherwise as assuming a co-coordinating role ${ }^{[15-17]}$. The WTO's supply side classification of tourism clearly illustrates this problem ${ }^{[10]}$. The fact that tourism is interpreted in varying ways and is spread across so many sectors is reflected in the range of educational approaches and content adopted.

The problem of definition is compounded by the international nature of tourism and the different activities on which it may be based within different countries. For example, the components of the tourism industry in a developing country may be relatively simple to identify as compared to the components of the tourism industry in an industrialized nation where sophisticated segmentation techniques result in a diverse range of market niches ${ }^{[9,10]}$. Consequently, the industry is much more complex and there are hundreds (or thousands) of operations that are influenced by the tourism industry; however, they may not have an obvious association with tourism.

It is clear, therefore, that without an agreed inventory of the activities and organizations that comprise the tourism industry, it is very difficult to design training and education to fully meet those needs ${ }^{[9]}$. With the tourism industry cutting across so many sectors and impinging upon such a wide range of operations, educators are faced with a bewildering choice of markets at which their products should be pitched ${ }^{[15]}$. It is against this background of fragmentation that tourism education has developed, and it is within this framework that the relationship between education and industry must evolve.

\subsection{Characteristics of the workforce}

There remains, in many societies, a cultural barrier to working in the service industry; employment in service industries in general is viewed as a low status career where individuals are neither invested in nor encouraged ${ }^{[9,11]}$. The workforce in tourism has traditionally been poorly rewarded by employers in terms of training, education, and financial rewards. As a result, the perception of tourism as an undesirable sector for employment perpetuates the situation to continue.

Most small and medium sized employers (and indeed some of the larger companies, too) have failed to recognize the benefits of training and education. Therefore, they do not finance these activities in a committed way ${ }^{[4,13]}$. Because employees are not invested in, they commonly feel no loyalty to the organization and are more inclined to move on ${ }^{[1]}$. As a result, the high turnover of staffs predominates, and it is little wonder that the characteristics of the transient and unprofessional tourism workforce do not change or improve ${ }^{[4]}$.

The problem is intensified by the fact that the industry is dominated by small businesses led by entrepreneurs who often possess no formal training or education in tourism. As a result, they neither 
recognize the need to invest heavily in training or education for their employees' self-development, nor do they recognize the benefits of such investment to their operations as a whole ${ }^{[14]}$.

The impression among those responsible for human resources in the tourism industry that there is no substitute for hands-on experience and no value in training or education is one that still predominates, representing a major barrier to the development of a cooperative relationship between the industry and education.

\subsection{Immaturity}

Many of the barriers to the implementation of full-scale training and education for tourism can be attributed to the immaturity of the tourism industry. International mass tourism is a relatively recent phenomenon, which did not evolve until the 1950s or the 1960s. As a result, the tourism industry by itself remains relatively young in comparison to other industries, and the educational approaches that have been developed to serve the industry are consequently still in their infancy. Tourism training has been established longer than tourism education, although by liberal estimates, it is still only 50 years of age. Tourism education, on the other hand, is much younger and despite the rapid progress of tourism as a subject area and the accompanying expansion in provision, the development of tourism courses at higher levels is characterized by a lack of planning and control ${ }^{[10]}$.

This relative immaturity is responsible for fueling many debates relating to the quality and delivery of tourism courses as well as the standards of teaching ${ }^{[4,5,9]}$; in addition, it has also generated speculations about other issues which require consideration.

Firstly, because tourism education is such a recent addition to the academic portfolio, it is still seeking to establish its credentials as an area worthy of serious academic study. It lacks the history and antecedents of the more mature fields, and it is troubled by conceptual weakness and fuzziness ${ }^{[9,10,15]}$. Educators, therefore, are facing with issues and problems which are taken as real in other disciplines; for example, discussion still persists in tourism over the definition of basic terms and concepts, the equivalent of which have long since been agreed upon in other subject areas ${ }^{[1,8]}$.

As a result, the framework for tourism education is fragmented and disjointed, and a clear direction for the sustained development of the subject is lacking. The integrative foundations that characterize other areas have not been developed yet by tourism educators, and the necessary preoccupation with establishing the basis for the subject area is a distraction for those wishing to build the "big picture" ${ }^{[9,15]}$. Derived from this lack of an overall perspective are several other problems. For example, there remains an ignorance of and a lack of credibility for the subject, and widespread prejudice as well as per-conceptions are rife among academics and non-academics alike who perceive tourism as a "soft" subject ${ }^{[9,10]}$.

\subsection{Human resource barriers to training}

As the recession has taken hold internationally, and major markets have gone into decline, the tourism industry increasingly finds that it has to rely on the skills, qualifications, knowledge, and expertise of its managers ${ }^{[9,10]}$. For larger companies where training and development programs have been established, management skills would ensure a more satisfactory response to the changing products and market needs. However, in smaller companies where training and education is limited or non-existent, the amateur management philosophy that predominates is likely to cause serious issues for many operations.

The "crisis management" techniques that have prevailed in tourism for so long are likely to lead to outmoded styles of management as well as instantaneous decision making driven by the needs of the moment and current operational demands ${ }^{[4,22-25]}$. This lack of planning is reflected in the human resource policies of organizations and enterprises in tourism or rather the absence of them ${ }^{[23,26]}$. The omission of 
suitable policies relating to human resources is the major reason why the industry has historically found it difficult to attract high caliber graduates; students considering a career in tourism are faced with the prospect of low starting salaries compared to other graduate recruiters, long hours, lack of training, limited career prospects, as well as little recognition of prior qualifications and achievements ${ }^{[9,10,27]}$. The career paths of graduates are also often unclear, and as a result, quality students are inclined to look elsewhere for opportunities, which offer a structured and integrated career development plan, where recruitment policies have been adapted to take into account of their experience in higher education ${ }^{[12,28,29]}$. Without serious consideration of these issues, the tourism industry would continue to surrender the best graduates to other industrial sectors, where personal development is encouraged and invested in, structured career paths are offered, and financial rewards commensurate with education and experience.

\section{Conclusion}

An interface between education and industry is instrumental in which without one, the other will falter. This study, in this manner, attempts to look for a connection between tourism education and training with entrepreneurship development, which is a significant worry of the tourism industry. The need of legitimate preparation and training is understood to guarantee an expert and gainful industry in business enterprise improvement. The tourism industry is a less paid worry among different divisions as it is viewed as one of the vital zones that can wipe out poverty on top of the nation's GDP. However, the hurdles in the tourism industry degrade it to be a less serious sector in contributing to previously mentioned activities. Therefore, eliminating the obstacles in the tourism industry is a crucial assignment of concern individuals engaged in this area. In gaining the principles of tourism education and the industry, educational programs for the tourism industry ought to be fused in the school level to higher education levels as an education plan. Last but not least, training for labor advancement for momentary yield, regardless of coaching, which has a long impact on both administration and individual, ought to be given.

\section{Disclosure statement}

The authors declare that there is no conflict of interest.

\section{References}

[1] Airey D, 2015, 40 Years of Tourism Studies: A Remarkable Story. Tourism Recreation Research, 40(1): 6-15.

[2] Airey D, Nightingale M, 1981, Tourism Occupations, Career Profiles and Knowledge. Annals of Tourism Research, 8(1): 52-68.

[3] Airey D, Tribe J, 2005, An International Handbook of Tourism Education, Elsevier, United Kingdom.

[4] Andrews S, 2007, Introduction to Tourism and Hospitality Industry, Tata McGraw-Hill Publishing Co., New Delhi.

[5] Chaskar A, 2009, Doing Research in Literature and Language (Researcher Companion), Vaibhav Publications, Pune.

[6] Manente M, Cerato M, (eds) 1991, Promoting Destinations Beyond the Year 2000 Opportunities and Threats, in Brackenbury M, From Destination to Destination Marketing and Management - Designing and Repositioning Tourism Products, CISET/University of Venice Press, Venezia, 45-48.

[7] Barr T, 1990, From Quirky Islanders to Entrepreneurial Magnates: The Transition of the Whitsundays. Journal of Tourism Studies, 1(2): 26-32. 
[8] Butler RW, 1980, The Concept of a Tourist Area Cycles of Evolution: Implications for Management of Resources. Canadian Geographer, 24(1): 5-12.

[9] Cobbinah PB, Black R, Thwaites RB, 2015, Biodiversity Conservation and Livelihoods in Rural Ghana: Impacts and Coping Strategies. Environmental Development, 15: 79-93.

[10] Cooper C, Shepherd R, 2014, The Relationship Between Tourism Education and the Tourism Industry: Implications for Tourism Education. Tourism Recreation Research, 22(1).

[11] Cooper C, Westlake J, 1989, Tourism Teaching into the 1990s. Tourism Management, 10: 69-73.

[12] Echtner CM, 1995, Tourism Education in Developing Nations: A Three-Pronged Approach. Tourism Recreation Research, 20(2): 32-41.

[13] Dahles H, Bras K, 1999, Tourism and Small Entrepreneurs: Development, National Policy, and Entrepreneurial Culture: Indonesian Cases. Cognizant Communication Corporation, New York.

[14] EIESP, 1991, Education for Careers in European Travel and Tourism. A Study Commissioned by the American Express Foundation. European Institution of Education and Social Policy, Paris.

[15] Faulkner B, 2000, The Future Ain't What It Used to Be: Coping with Change, Turbulence and Disasters in Tourism Research and Destination Management. Griffith University, Gold Coast.

[16] Gonnsen E, 1981, The Spatio-Temporal Development of International Tourism: Attempt at a CentrePeriphery Model, SAGE Publication, London.

[17] Gracia S, Rachel D, 2010, Sustainable Tourism in Island Destinations, Earthscan, London.

[18] Haywood KM, 1989, Managing Word-of-Mouth Communications. Journal of Service Marketing, 3(2): 55-67.

[19] Ritchie JRB, Hawkins D, (eds) 1992, A Conceptual Model of the Education/Employment Interface for the Tourism Industry, in Haywood KM, Maki K, World Travel and Tourism Review, CAB, Oxford, 237-248.

[20] Jafari J, 1990, Research and Scholarship: The Basis of Tourism Education. Journal of Tourism Studies, 1(1): 407-429.

[21] Jafari J, Ritchie B, 1981, Towards a Framework for Tourism Education. Annals of Tourism Research, 8: 13-33.

[22] Koh KY, 1996, The Tourism Entrepreneurial Process: A Conceptualization and Implications for Research and Development. The Tourist Review, 51(4): 24-41.

[23] Laws E, Faulkner B, Moscardo G, (eds) 1998, Planning for Stability and Managing Chaos: The Case Of Alpine Ski Resorts, in Lewis R, Green S, Embracing and Managing Change in Tourism: International Case Studies, Routledge, London, 138-160.

[24] Mathieson A, Wall G, 1982, Tourism: Economic, Physical and Social Impacts, Longman, London.

[25] Neblett J, 2000, Linking Development, Indigenous Entrepreneurship and Tourism, with Special Reference to Barbados. Geography Online, 1(2).

[26] Parsons D, Cave P, 1990, Developing Managers for Tourism, Nedo, London.

[27] Sears GJ, Bara VV, 2011, Toward a Multistage, Multilevel Theory of Innovation. Canadian Journal of Administrative Sciences, 28(4): 357-372.

[28] Shaw G, Williams AM, 2004, Tourism and Tourism Spaces, SAGE Publication, London.

[29] Ioannides D, Debbage KG, (eds) 1998, Entrepreneurship and Small Business Culture and Tourism Development, in Shaw G, Williams AM, The Economic Geography of the Tourist Industry: A SupplySide Analysis, Routledge, London. 